\title{
The Structural Model of Educational Self-regulation Based on Learning Strategies and Attributional Styles by the Mediator of Achievement Motivation Among Secondary High School Students in Sari in 2017-2018
}

\author{
Kheironesa Shirdel ${ }^{1}$, Mohammad Kazem Fakhri $^{*}$, Bahram Mirzaeyan ${ }^{1}$ \\ 'Department of Psychology, Sari Branch, Islamic Azad University, Sari, Iran
}

\begin{abstract}
Background: Achievement motivation is one of the critical variables that predict educational achievement and success in the future. Therefore, the identification of effective factors upon achievement motivation may be one of the basic subjects in education. The present study aimed to evaluate the structural model of educational self-regulation based on learning strategies by the mediator of achievement motivation among students.

Methods: The present study was correlation research with structural equation modeling (SEM). The statistical universe of this study consisted of all boy and girl students at secondary high schools in 2017-2018. The multistep random cluster sampling selected 375 (215 girls and 160 boys). Data gathered by the Bouffard educational self-regulation questionnaire, learning strategies questionnaire, attributional style questionnaire, and Herman's achievement motivation questionnaire. Data analysis gathered by path analysis and structural equations with Lisrel 8.80 software.

Results: The research results indicated the direct effects of learning strategies and attributional styles upon achievement motivation $(P<0.05)$. Also, model fitting indicated indirect effects of learning strategies and attributional styles by achievement motivation upon students learning self-regulation $(P<0.01)$.

Conclusion: Research results indicate that self-regulation learning strategies are educational. The teaching of these strategies is effective in increasing internal attribution style for positive events and decreasing this style for adverse events among students.

Keywords: Self-regulation; Learning strategies; Attributional styles; Achievement motivation.
\end{abstract}

*Correspondence to Mohammad Kazem Fakhri, Department of Psychology, Sari Branch, Islamic Azad University, Sari, Iran Email: Fakhry1386@gmail.com

Published online 30 September 2018

Citation: Shirdel K, Fakhri MK, Mirzaeyan B. The structural model of educational self-regulation based on learning strategies and attributional styles by the mediator of achievement motivation among secondary high school students in Sari in 2017-2018. Int Clin Neurosci J. 2018;5(3):92-97. doi:10.15171/icnj.2018.18.

\begin{abstract}
Introduction
Achievement motivation is one of the critical variables that predict educational achievement and success in the future. Therefore, the identification of effective factors upon achievement motivation may be one of the basic subjects in education. ${ }^{1}$ Students with achievement motivation try to success in one education course and achievement is more important than a reward for them. ${ }^{2}$ Researches show the positive correlation between motivation and performance among students. ${ }^{3,4}$ Moreover, the results of different studies have shown the effect of individual and social factors on achievement motivation. Education situation, teacher, attachment to university, learning experiences quality, a person's self-efficacy, and endurance rate are effective upon student's motivation. ${ }^{5-11}$ Self-regulation learning is the other important variable in learning. ${ }^{12}$ Before the 1980s, self-regulation learning studies concentrated on
\end{abstract}

the individual, family, and social fields but after that, it stated in the learning field. ${ }^{13}$ Some theorists state that self-regulation explains the difference between successful and unsuccessful students. ${ }^{14}$ Zimmerman and Pons stated basic form of self-regulation of learning theory; this theory is learning organization method by students metacognitively, motivationally and behaviorally. ${ }^{15}$ Self-regulation helps to control and orient actions by students. ${ }^{16}$ Jarvela and Jarvenoja believe that it is useful to create better learning habits and improve studying skills. ${ }^{17}$ Self-regulation is effective in success in academic skills like regulation of goals, choosing, replacement of strategies and useful control. ${ }^{18}$ Peck and Miller believe that more application of these strategies may result in better action and more success. ${ }^{19}$ Berger and Karabenick stated that motivation and self-regulation are related to each other. Self-regulation is an organized activity

(C) 2018 The Author(s). This is an open access article distributed under the terms of the Creative Commons Attribution License (http:// creativecommons.org/licenses/by/4.0/), which permits unrestricted use, distribution, and reproduction in any medium, provided the original work is properly cited. 
that helps the person to have some goals for learning and, in turn, control behaviors. ${ }^{20}$ Bembenutty indicated that learners with high self-regulation learning tend to postpone their needs satisfaction. They have internal interest in lessons and are more active to complete lessons tasks. ${ }^{21}$ Some studies show that successful students have the high internal motivation and act well. ${ }^{20,22}$ According to studies results, a self-regulation learning strategy teaching improves self-efficacy and motivation. ${ }^{23}$ Learning strategies are fundamental in student's motivation. They are used to encode and remember. ${ }^{24}$ One of the best classifications from learning strategies is the analysis of learning strategies into 2 groups including cognitive and metacognitive strategies. Cognitive strategies used in content learning and metacognitive strategies are used to control cognitive strategies. ${ }^{25}$ These strategies help to store new information in long-term memory. ${ }^{26}$ Metacognitive strategies help to supervise upon cognitive strategies and improve student achievement. ${ }^{27}$ Attributional styles are other basic variables to determine a student's success or failure; Attribution style refers to reasons for pleasant or unpleasant events. The attributional style is a process in which people about causal factors of an event or incident decide based on ability, effort, difficulty level, and responsibility. ${ }^{28}$ Heider $^{29}$ believes that there are two major attributions or the method of behavior interpretation, internal and external. Internal attribution ascribes behavior to individual features, internal reasons, stable and total and external attribution style ascribes to environment factors, external reasons, unstable and special. Persons with pessimistic style have internal, stable and total explaining for unpleasant events and persons with optimistic style have external, variable and special explaining for unpleasant events. ${ }^{29}$ Weiner believes that attributional reasons for success or failure include three dimensions like locus, stability, and control. Locus dimension is related to personal behavior (internal) or some external variables. Stability dimension differentiates reasons from their durability. Control dimension is related to personal control rate upon reason. ${ }^{30}$ Such research has not executed in Iran; however, achievement motivation mediator role as a process variable in the relationship with cognitive and metacognitive factors has been important for previous researchers. Educational carelessness as the criterion variable has not been dramatic for researchers. Therefore, the present study aimed to determine achievement motivation mediator role in the relationships among educational carelessness, learning study strategy and attributional styles. In other words, the basic aim of the present study was to test causal model for relations between educational carelessness and identification of direct and indirect effects upon learning strategies (cognitive and metacognitive) and attributional styles with achievement motivation mediator among students.
Methods

The present study was correlation research with structural equation modeling (SEM). The statistical universe of this study consisted of all boy \& girl students of secondary high schools in 2017-2018. 375 students (215 girls and 160 boys) selected by multistep random cluster sampling. Data gathered by Bouffard educational self-regulation questionnaire, learning strategies questionnaire, attributions style questionnaire, and Hermans achievement motivation questionnaire. Before executing research, all participants were informed and received their satisfaction. Data analysis gathered by SEM and Lisrel 8.80 software.

\section{Measures}

Bouffard Educational Self-regulation Questionnaire (1955)

Bouffard educational self-regulation 14-item questionnaire has been designed to measure self-regulation based on Bandura cognitive-social theory. ${ }^{31}$ Questions measure three sub-scales including cognitive strategies (5 items), metacognitive (6 items) and motivational strategies (3 items) by the Likert scale from "I agree completely" to "I disagree completely." Questions 5, 13 and 14 scored inversely. Results of the factorial analysis indicate that this instrument may explain 0.52 self-regulation variance. The reliability coefficient of the whole questionnaire by Cronbach $\alpha$ is 0.71 and 0.70 for cognitive strategies subscale and 0.68 for metacognitive subscale. ${ }^{31}$ Talebzadeh Nobarian et al reported reliability coefficient of the whole questionnaire based on Cronbach $a 0.76 .^{32}$

\section{Learning Strategies Questionnaire}

Shahram Ohadi has designed it based on self-regulation learning theory Pintrich and Degrooth in 1997 (5 components). ${ }^{33}$ Mir Abbas Mousavian changed this questionnaire into 6 components in 2004. Subjective review or repetition strategies have 5 questions; semantic expansion has 6 questions, organization and question strategies have 6 questions, planning has 6 questions, monitoring and controlling strategies have 4 questions and regulating have 3 questions. The number of questionnaire questions is 30 items, which are scored based on the Likert scale with always (3), usually (2), sometimes (1) and never (0). Questionnaire reliability by Cronbach $\alpha$ has been reported to be 0.78 .

\section{Attributional Style Questionnaire}

This questionnaire has been designed by Peterson and colleagues for determining people attributional style, i.e., control locus (internal vs. external), stability rate (stable vs. temporary), totality (global vs. specific) and control ability (controllable/uncontrollable). Sheikholeslami translated it into Persian in 1998. This instrument measures persons' tendency toward pleasant and unpleasant events reason by internal factors (against external), stable (against 
unstable), general (against special). ${ }^{34}$ This scale consists of 12 hypothetical situations (positive situations 6 \& negative situations 6). Four questions stated for each situation. The first question (in the form of descriptive responding) asks one main reason that is not considered for scoring but helps to subject to respond to the next 3 questions. The next three questions are similar for all situations and measure causal attributions dimensions. The second question measures a person's answer internal or external being. The third question determines stability/ nonstability of the subject responding, and finally, the fourth question determines to be general/special of subject response. Score 1 is the worst state, and score 7 is the best state for each positive events and negative situations, scoring is inverse. For each situation, the subject must imagine each of the events in his/her mind and then write one reason, which seems the most important reason for that event. Bridges ${ }^{35}$ has reported Cronbach a coefficient of this questionnaire 0.80 and Soleimani and Habibi have been reported 0.74 in Iran. ${ }^{36}$

\section{Hermans Achievement Motivation Questionnaire}

This scale by Hermans includes 29 sentences scored from 1 to 4 orderly, and in some questions, they scored inversely. High scores indicate high achievement motivation. ${ }^{37}$ Hermans reported its reliability by re-test method 0.84 . Nouhi and colleagues confirmed its validity and reliability. ${ }^{38}$

Table 1. Fitting Indexes for the Structural Model

\begin{tabular}{lc}
\hline Indexes & Finding \\
\hline Chi-square & 68.13 \\
$P$ value & 0.0001 \\
Degrees of freedom $(d f)$ & 23 \\
Root mean square error of approximation (RMSEA) & 0.076 \\
Non-normed fit index (NNFI) & 0.90 \\
Normed fit index (NFI) & 0.91 \\
The adjusted goodness of fit index (AGFI) & 0.92 \\
The goodness of fit index (GFI) & 0.96 \\
Comparative fit index (CFI) & 0.94 \\
Incremental fit index (IFI) & 0.94 \\
\hline
\end{tabular}

Results

In this study, $57.3 \%$ and $42.7 \%$ of the respondents were girl's boys, respectively. Data analysis is done after confirming data being normal. Table 1 indicates that all fitting indicators are higher than 0.90; therefore, these indexes indicate suitable fitting of the formulated model. Root mean error of approximation (RMSEA) was 0.076. Since value below 1 for this index is suitable, therefore, the model range seems acceptable. Chi-square value is 68.13 , and degree freedom also is $23\left(\frac{68.13}{23}=2.96\right)$, since it is between 1 and 3 range. Therefore, the model is suitable. In other words, the formulated model has the good fitting. Table 2 indicates the standard coefficients of variable effects upon each other.

According to Table 2, learning strategies affect achievement motivation directly $(P<0.05, \beta=0.359)$. It means that learning strategies may predict achievement motivation. Learning strategies also by achievement motivation affect self-regulation indirectly $(\beta=0.40$, $P<0.01)$. These results indicate the significant structural relationship between learning strategies and selfregulation. In other words, students with learning study strategies act in self-regulatory educational programs. Achievement motivation path coefficient upon selfregulation is significant $(P=1.16, P<0.01)$. We can state that students with achievement motivation are more successful in self-regulation. According to table results, attributional styles affect achievement motivation directly $(\beta=0.41, P<0.05)$. It means that attributional styles may predict achievement motivation. Attributional styles also by achievement motivation affect upon selfregulation indirectly $(\beta=0.84, P<0.01)$. These results indicate the significant structural relationship between attributional styles and self-regulation. In other words, students with attributional styles act in self-regulatory educational programs. The results of this table also show that achievement motivation path coefficient upon self-regulation is significant $(\beta=1.16, P<0.01)$. High achievement motivation coefficient may predict self-regulation. Therefore, we can state that learning study strategies and attributional styles by the mediator of achievement motivation may predict self-regulation. Students use learning cognitive strategies to success in self-regulation (Figures 1 and 2).

Table 2. Direct and Indirect Standard Effects and Variables Total Effect Determining the Coefficient

\begin{tabular}{|c|c|c|c|c|c|}
\hline Effect (From Variable Upon Variable) & Direct Effect & Indirect Effect & $t$ Value & Total Value & $\mathbf{R}^{2}$ \\
\hline Learning strategies upon achievement motivation & 0.35 & - & 4.11 & 0.35 & 0.42 \\
\hline Learning strategies upon self-regulation & 0.41 & - & 4.17 & 0.41 & 0.42 \\
\hline Attributional styles upon achievement motivation & 0.41 & - & 4.17 & 0.41 & 0.31 \\
\hline Attributional styles upon self-regulation & - & 0.48 & 5.31 & 0.48 & 0.42 \\
\hline Achievement motivation upon self-regulation & 1.16 & - & 5.36 & 1.16 & 0.35 \\
\hline
\end{tabular}




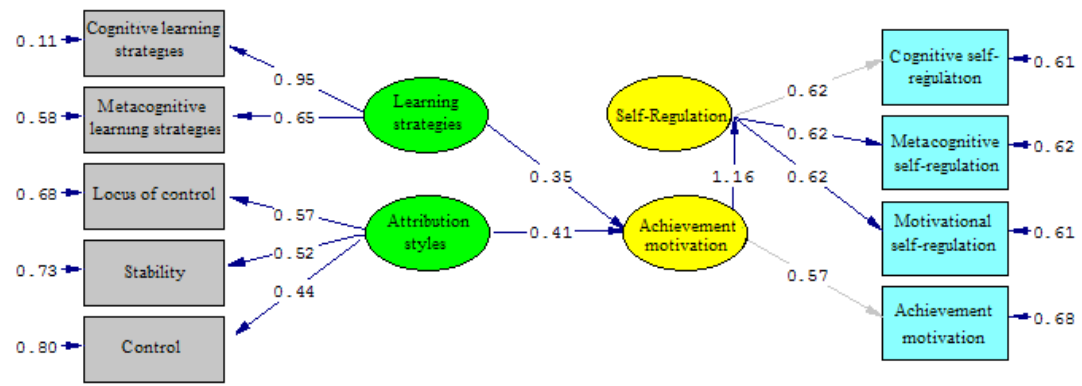

Chi-Square $=68.13, \mathrm{df}=23, \mathrm{P}-\mathrm{value}=0.00000, \mathrm{RMSEA}=0.076$

Figure 1. Structural Equations Modeling of Conceptual Research Model (Approximation Standard Coefficients).

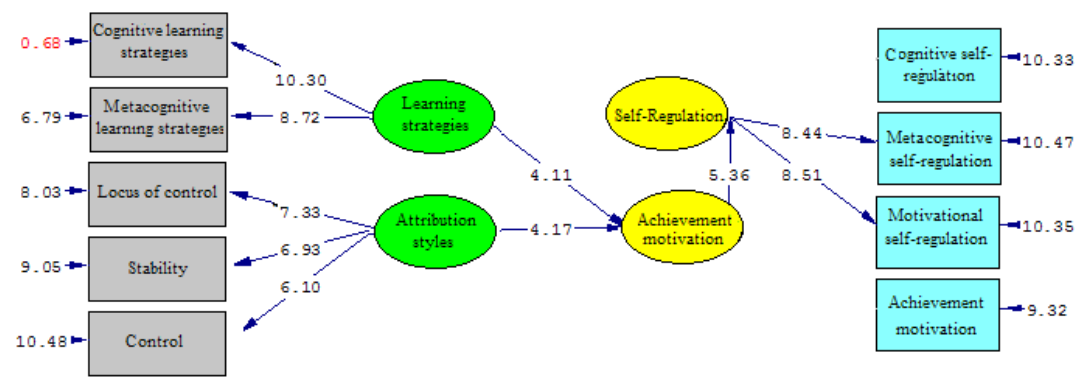

Chi-Square $=68.13, \mathrm{df}=23, \mathrm{P}-$ value $=0.00000, \mathrm{RMSEA}=0.076$

Figure 2. Structural Equations Modeling of Conceptual Research Model (Significance Standard Coefficients).

\section{Discussion}

The aim of the present study was the structural study of educational self-regulation based on learning strategies and attributional styles with the mediator of educational motivation among students. The results showed that learning strategies affect upon achievement motivation directly. Also, learning strategies affect upon self-regulation by achievement motivation indirectly. Also, attributional styles affect upon self-regulation by achievement motivation indirectly. These results indicate one significant structural relationship among attributional styles with self-regulation. We can state that studies with high attributional styles are more successful in selfregulation by using high achievement motivation and use locus of control variable to success in self-regulation. Inconsistent with findings of the current study, Leins concluded that learning strategies training improved good events attributions styles for experimental group than the control group and also decreased bad events attributional styles significantly. ${ }^{39}$ Nikpey et $\mathrm{al}^{40}$ and Ahanchiyan et $\mathrm{al}^{41}$ indicated the significant relationship between selfregulation learning strategies and attributional styles. However, our study findings are not consistent with the findings of Marsh et $\mathrm{al}^{42}$ and Claes et al. ${ }^{43}$ They found that self-regulation does not predict attributional style among students. Students with self-regulation strategies have internal, stable and total attribution style for good events and external, unstable and special attribution style for bad events. Therefore, making informed students about self-regulation strategies and using them in learning may be effective in their attribution style. ${ }^{40}$ The other findings indicated a significant structural relationship between learning strategies with self-regulation, we can conclude that learning strategies may predict self-regulation. These findings are inconsistent with Aksan research, and he found that self-regulation interventions improved learning and decreased being inactive. ${ }^{44}$ Pintrich states that self-regulation is an active process to regulate learning goals and control upon cognition, motivation, and behavior. ${ }^{45}$ Malmberg found that self-regulation training may be effective in using cognitive regulation strategy. Students may master upon their learning process by some skills like organization and knowledge storing, using strategies to review and store information in their memory such as conceptual plan and encoding and mind regulating strategies training. Self-regulated students try to learn and improve their educational performance by creating the relationship between previous information and new information, controlling this process and creating a suitable learning environment. ${ }^{46}$ The other 
results of this study indicate that students with high achievement motivation success in self-regulation well. These findings are inconsistent with Yasaminejad et $\mathrm{al}^{47}$ Ning \& Downing, ${ }^{22}$ and Berger \& Karabenick. ${ }^{20}$ They believe that there is the significant relationship between self-regulation (cognitive \& metacognitive) upon motivational believes (educational motivation). In other words, self-regulation strategies may improve the student's educational motivation. Malekian and colleagues found that expansion strategy is more important than the other self-regulation learning strategies in student's achievement motivation. ${ }^{48}$

Moreover, the findings of the study by Usher and Pajares are indicative of the fact that the beliefs of students about with adjusted self-regulation learning strategies play an essential role in their success and achievement motivation. ${ }^{49}$ It should note that students with adjusted self-regulation learning strategies show features like trying to success, enjoying from challenging activities, fit activities. More awareness may result in better analysis and behavior. One of the limitations of the current study was the fact that its data were collected by questionnaires, which may have falsified because of the unconscious orientation of many respondents. Additionally, the present research performed in the city of Sari; thus, in the generalization of the obtained results for other cities, all aspects should be considered.

\section{Conclusion}

Research results indicate that self-regulation learning strategies are educational and effective in increasing internal attribution style for positive events and decreasing this style for negative events. Teachers may regulate students learning by correct education methods; since self-regulation is dependent on teachers awareness from self-regulation strategies method, therefore, it is better that self-regulating teachers should regard as main goals of education and universities.

\section{Conflict of Interest Disclosures}

The authors declare that they have no conflict of interests.

\section{Ethical Statement}

Not applicable.

\section{References}

1. Mega C, Ronconi L, De Beni R. What makes a good student? How emotions, self-regulated learning, and motivation contribute to academic achievement. J Educ Psychol. 2014;106(1):121-31. doi: 10.1037/a0033546.

2. Pourkarimi J, Mobinrahni Y. Relationship between Achievement Motivation and Academic Burnout Mediating Role of Self-Efficacy Tehran University students. Educ Strategy Med Sci. 2018;11(1):139-47. doi: 10.29252/ edcbmj.11.01.18.

3. Emmanuel AO, Adom EA, Josephine B, Solomon FK. Achievement motivation, academic self-concept and academic achievement among high school students.
European Journal of Research and Reflection in Educational Sciences. 2014;2(2):24-37.

4. Parishani N, Mirshah Jafari S, Abedi A. Effect of Technology Enabled Active Learning in the lesson of biology on the students' motivation. Journal of Education and Learning. 2011;3(1):1-16.

5. Yazdi-Ravandi S, Taslimi Z, Ghaleiha A, Azhdarloo M, Shamsaei F. Knowledge and Attitude in Hamadan University of Medical Sciences Students toward AIDS: A Cross- Sectional Study from West of Iran. Int Clin Neurosci J. 2017;4(3):103-6.

6. Lee $W$, Lee MJ, Bong M. Testing interest and self-efficacy as predictors of academic self-regulation and achievement. Contemp Educ Psychol. 2014;39(2):86-99. doi: 10.1016/j. cedpsych.2014.02.002.

7. Karshaki H, Momeni Mahmouei H, Qureishi B. Comparison of educational motivation and quality of life of male students, subjected to descriptive evaluation with the traditional evaluation. Curriculum Planning Knowledge \& Research in Educational Sciences. 2014;11(13):104-14.

8. Maurer TW, Allen D, Gatch DB, Shankar P, Sturges D. Students' academic motivations in three disciplines. Journal of the Scholarship of Teaching and Learning. 2013;13(5):7789.

9. Yazdi-Ravandi S, Taslimi Z, Ahmadpanah M, Ghaleiha A. Adjustment to diabetes among diabetic patients: the roles of social support and self-efficacy. Avicenna Journal of Neuro Psycho Physiology. 2016;3(1):1-5. doi: 10.17795/ ajnpp-37470.

10. Komarraju $M$, Nadler D. Self-efficacy and academic achievement: Why do implicit beliefs, goals, and effort regulation matter? Learn Individ Differ. 2013;25:67-72. doi: 10.1016/j.lindif.2013.01.005.

11. Yazdi-Ravandi S, Taslimi Z, Jamshidian N, Saberi H, Shams J, Haghparast A. Prediction of Quality of life by Self-Efficacy, Pain Intensity and Pain Duration in Patient with Pain Disorders. Basic Clin Neurosci. 2013;4(2):117-24.

12. Hen $M$, Goroshit $M$. Academic procrastination, emotional intelligence, academic self-efficacy, and GPA: a comparison between students with and without learning disabilities. J Learn Disabil. 2014;47(2):116-24. doi: 10.1177/0022219412439325.

13. Bembenutty $\mathbf{H}$. Self-regulation of learning and academic delay of gratification: Gender and ethnic differences among college students. J Adv Acad. 2007;18(4):586-616. doi: 10.4219/jaa-2007-553.

14. Bandura A. Social cognitive theory of self-regulation. Organ Behav Hum Decis Process. 1991;50(2):248-87. doi: 10.1016/0749-5978(91)90022-L.

15. Zimmerman BJ, Martinez-Pons M. Development of a structured interview for assessing student use of self-regulated learning strategies. Am Educ Res J. 1986;23(4):614-28. doi: 10.3102/00028312023004614

16. Zimmerman BJ. Self-Regulated Learning: Theories, Measures, and Outcomes. Oxford: Elsevier; 2015.

17. Jarvela S, Jarvenoja $H$. Socially constructed self-regulated learning and motivation regulation in collaborative learning groups. Teach Coll Rec. 2011;113(2):350-74.

18. Phan HP. Critical thinking as a self-regulatory process component in teaching and learning. Psicothema. 2010;22(2):284-92.

19. Peck B, Miller C. I think I can, I think I can, I think I can...I know I can Multi-user Virtual Environments (MUVEs) as a means of developing competence and confidence in undergraduate nursing students An Australian perspective. Procedia Soc Behav Sci. 2010;2(2):4571-5. doi: 10.1016/j. sbspro.2010.03.732. 
20. Berger JL, Karabenick SA. Motivation and students' use of learning strategies: Evidence of unidirectional effects in mathematics classrooms. Learn Instr. 2011;21(3):416-28. doi: 10.1016/j.learninstruc.2010.06.002.

21. Bembenutty $\mathbf{H}$. Homework completion: The role of selfefficacy, delay of gratification, and self-regulatory processes. Int J Educ Psychol Assess. 2010;6(1):1-20.

22. Ning HK, Downing K. The reciprocal relationship between motivation and self-regulation: A longitudinal study on academic performance. Learn Individ Differ. 2010;20(6):6826. doi: 10.1016/j.lindif.2010.09.010.

23. Alexiou A, Paraskeva F. Inspiring Key Competencies Through the Implementation of an ePortfolio for Undergraduate Students. Procedia Soc Behav Sci. 2015;197:2435-42. doi: 10.1016/j.sbspro.2015.07.307.

24. Tuncer U. How do monolingual and bilingual language learners differ in use of learning strategies while learning a foreign language? Evidences from Mersin University. Procedia Soc Behav Sci. 2009;1(1):852-6. doi: 10.1016/j. sbspro.2009.01.153.

25. Royanto LRM. The Effect of An Intervention Program based on Scaffolding to Improve Metacognitive Strategies in Reading: A Study of Year 3 Elementary School Students in Jakarta. Procedia Soc Behav Sci. 2012;69:1601-9. doi: 10.1016/j. sbspro.2012.12.105.

26. Ashoori J, Azadmard S, Jalil Abkenar S, Moeinikia. A prediction model of academic achievement based on cognitive and metacognitive strategies, achievement goals orientation and spiritual intelligence in biology. J Sch Psychol. 2014;2(4):11836 .

27. Pakdaman Savoji A, Niusha B, Boreiri L. Relationship Between Epistemological Beliefs, Self-regulated Learning Strategies and Academic Achievement. Procedia Soc Behav Sci. 2013;84:1160-5. doi: 10.1016/j.sbspro.2013.06.719.

28. Weiner B. An attribution theory of motivation and emotion. Series in Clinical \& Community Psychology: Achievement, Stress, \& Anxiety. New York: Springer-Verlag; 1982. p. 223-45.

29. Heider F. The psychology of interpersonal relations. New Jersey: Psychology Press; 2013.

30. Weiner B. The Attribution Approach to Emotion and Motivation: History, Hypotheses, Home Runs, Headaches/Heartaches. Emot Rev. 2014;6(4):353-61. doi: 10.1177/1754073914534502.

31. Bouffard T, Boisvert J, Vezeau C, Larouche C. The impact of goal orientation of self-regulation and performance among college students. Br J Educ Psychol. 1995;65(3):317-329. doi: 10.1111/j.2044-8279.1995.tb01152.x.

32. Talebzadeh Nobarian M, Abolghasemi F, Ashourinejad S, Mousavi H. A Causal Model for Self-Concept, SelfRegulatory Learning and Academic Achievement. Journal of Psychological Models and Methods. 2010;1(4):65-79.

33. Pintrich PR, de Grooth EV. Motivational and self-regulated learning components of classroom academic performance. J Educ Psychol. 1990;82(1):33-40. doi: 10.1037/00220663.82.1.33.

34. Peterson C, Semmel A, von Baeyer C, Abramson LY, Metalsky GI, Seligman ME. The attributional style questionnaire. Cognit Ther Res. 1982;6(3):287-99. doi: 10.1007/BF01173577.

35. Bridges KR. Using attributional style to predict academic performance: how does it compare to traditional methods? Pers Individ Dif. 2001;31(5):723-30. doi: 10.1016/S01918869(00)00174-4.

36. Soleimani E, Habibi Y. The relationship between emotion regulation and resiliency with psychological well-being in students. J Sch Psychol. 2014;3(4):51-72.

37. Hermans HJ. A questionnaire measure of achievement motivation. J Appl Psychol. 1970;54(4):353-63.

38. Nouhi S, Hoseini M, Rokhsarizadeh H, Saburi A, Alishiri G. Progress Motivation among Baqiyatallah University of Medical Sciences Students and Its Relationship with Academic Achievement. J Mil Med. 2012;14(3):200-4.

39. Leins JE. Self-regulated strategy instruction with the selfregulation micro-analytic assessment and attribution training in high school students with learning disabilities. Fairfax, USA: George Mason University; 2011

40. Nikpey I, Farahbakhsh S, Yosefvand L. The Effect of SelfRegulated learning Strategies (Cognition and Meta Cognition) the Attribution Styles and Its Dimensions (Source causality, Proof of causality, general causation) of The Second High School Students. Biquarterly Journal of Cognitive Strategies in Learning. 2017;4(7):93-108. doi: 10.22084/j. psychogy.2017.1655.

41. Ahanchiyan M, Arfaa F, Bahmanabadi S. The association between attribution style and self regulation among students of School of Nursing and Midwifery in Mashhad University of Medical Sciences during 2011-12 academic years. Iran J Med Educ. 2014;14(4):350-62.

42. Marsh R, Steinglass JE, Gerber AJ, Graziano O'Leary K, Wang $Z$, Murphy D, et al. Deficient activity in the neural systems that mediate self-regulatory control in bulimia nervosa. Arch Gen Psychiatry. 2009;66(1):51-63. doi: 10.1001/ archgenpsychiatry.2008.504.

43. Claes L, Vertommen S, Smits D, Bijttebier P. Emotional reactivity and self-regulation in relation to personality disorders. Pers Individ Dif. 2009;47(8):948-53. doi: 10.1016/j. paid.2009.07.027.

44. Aksan N. A descriptive study: epistemological beliefs and self regulated learning. Procedia Soc Behav Sci. 2009;1(1):896901. doi: 10.1016/j.sbspro.2009.01.159.

45. Pintrich PR. A conceptual framework for assessing motivation and self-regulated learning in college students. Educ Psychol Rev. 2004;16(4):385-407. doi: 10.1007/s10648-004-0006-x.

46. Malmberg J. Tracing the process of self-regulated learning students' strategic activity in $\mathrm{g} / \mathrm{n}$ Study learning environment. Finland: University of Oulu; 2014.

47. Yasaminejad P, Taheri M, Golmohammadian M, Ahadi H. The relationship between self-regulation and achievement motivation and academic achievement of high school female students in Tehran. Training \& Learning Researches. 2014;20(3):325-38. [Persian].

48. Malekian F, Narimani M, Sahebjami S. The role of cognitive and meta-cognitive strategies in achievement motivation of learners of the educational system based on information and communication technology. Research in Curriculum Planning. 2010;1(25):21-38. [Persian].

49. Usher EL, Pajares F. Sources of self-efficacy in mathematics: A validation study. Contemp Educ Psychol. 2009;34(1):89-101. doi: 10.1016/j.cedpsych.2008.09.002. 